\title{
Development of variable renewable energy policy in developing countries: a case study of Sri Lanka
}

\author{
Xunpeng Shi* \\ Energy Studies Institute, \\ National University of Singapore, \\ 119620, Singapore \\ Email: shi@nus.edu.sg \\ *Corresponding author

\section{Hengsi Chen}

Research Group Network Planning and Network Operation, Institute of Power Systems and Power Economics,

RWTH Aachen University,

Aachen, Germany

Email: hc@iaew.rwth-aachen.de

\section{Yang Yu}

Civil and Environmental Engineering,

Stanford University,

Stanford, California, 94305, USA

Email: yangyu1@stanford.edu

\section{Fushuan Wen}

Department of Electrical and Electronic Engineering, Universiti Teknologi Brunei (Brunei University of Technology), Bandar Seri Begawan BE1410, Negara Brunei Darussalam Email: fushuan.wen@gmail.com

\begin{abstract}
Development of policy for variable renewable energy (VRE), such as wind and solar power, could be difficult in developing countries that have limited capacity, limited technical, and fiscal resources. Sri Lanka is such a case. Although Sri Lanka has a potential to develop VRE, the development was neither sufficient nor smooth. This study explores the development of VRE in the 2000s and analyses the impacts of the cost reflective feed-in-tariffs (FITs). The study finds that VRE public policy in Sri Lanka can be improved in a number of ways: better coordination among government agencies; technology specific policy and accommodation of cost dynamics; and redesign of subsidy policies. Generally, the governance mechanism suggested in this research is an
\end{abstract}


innovated structure to coordinate multiple government agencies by specifying policies according to technologies and redesigning the subsidy structures by accommodating the cost dynamics.

Keywords: Sri Lanka; variable renewable energy; VRE; feed-in-tariff; FIT; stakeholder impact assessment.

Reference to this paper should be made as follows: Shi, X., Chen, H., $\mathrm{Yu}, \mathrm{Y}$. and Wen, F. (2018) 'Development of variable renewable energy policy in developing countries: a case study of Sri Lanka', Int. J. Public Policy, Vol. 14, Nos. 1/2, pp.10-29.

Biographical notes: Xunpeng Shi is Senior Fellow and Deputy Head of the Energy Economic Division at the Energy Studies Institute, National University of Singapore. Previously, he worked in China, Indonesia and Brunei on national and regional policy issues. He is an Associate Editor of Journal of Management for Modelling. His areas of expertise include natural gas pricing, energy market integration and connectivity, renewable energy, energy efficiency with a regional focus of ASEAN, and Northeast Asia, and the Chinese economy. He obtained his $\mathrm{PhD}$ of Economics and Master of Environmental and Resource Economics from the Australian National University, LLM in Mineral Law and Policy form University of Dundee and Bachelor in Marketing from China University of Mining and Technology.

Hengsi Chen is a Research Assistant at the Institute of Power Systems and Power Economics (IAEW) of RWTH Aachen University since 2012, and had studied Electrical Power Engineering (Master) at RWTH Aachen University in Germany and Electric Power Engineering and Automation (Bachelor) at Shanghai Jiao Tong University in China. His PhD dissertation deals with technical potential of distribution networks (smart grids) for providing flexibility considering uncertainties.

Yang $\mathrm{Yu}$ is a $\mathrm{PhD}$ candidate in Stanford University. His researches focus on renewable energy policy, electricity market design, climate change strategy, energy transition and system operation in developing countries. He received his Master degree from Department of Economics in Stanford during his $\mathrm{PhD}$ study. He was a Pre-Doctor Fellow of Stanford Center at Peking University. Before entering Stanford, he received his Master degree from School of Engineering in Nanjing University and Bachelor degree from Department of Mathematics in Nanjing University.

Fushuan Wen is a Professor with Universiti Teknologi Brunei (Brunei University of Technology) Brunei, taking leave from Zhejiang University where he has been a Full Professor and the Director of the Institute of Power Economics and Information since 1997. He was a University Distinguished Professor and the Deputy Dean of the School of Electrical Engineering in South China University of Technology, Guangzhou, China, from 2005 to 2009. His research interests lie in electricity markets smart grids and electric vehicles. $\mathrm{He}$ is an Associate Editor of IET Generation, Transmission \& Distribution. He received his BE and ME degrees from Tianjin University, Tianjin, China, and $\mathrm{PhD}$ from Zhejiang University, Hangzhou, China, all in Electrical Engineering. 


\section{Introduction}

In the last few decades, many countries have formed and modified their policy portfolios to encourage renewable energy (RE, primarily, small hydropower, wind and solar PV) utilisation. These portfolios are all made up of a series of policies that facilitate RE investment in capacity installation, risk control, and electricity generation. These policies can be mainly classified into three types: subsidies for generation and installation, including guaranteed revenue through feed-in-tariffs (FITs); bidding and scheduling policies that reduce risks from the uncertainty of RE for investors; and renewable portfolio standards or targets. According to the IEA/IRENA Joint Policies and Measures Database (IEA and IRENA, 2016), as of May 2015, among the 129 countries in the database, there were 116 FITs in force and 59 national targets for solar and wind energy in force. With the aid of these policies, variable renewable energies (VREs) such as wind power and solar photovoltaic power have progressed well.

However, these renewable policies could be unsustainable and hard to replicate in developing countries. Many developing countries have pro-RE policy but may not have the technical, financial or even financial resources to replicate the policy that is successful in developed countries (Shi, 2016). When the RE penetration level becomes significantly high, the prevailing favourable policies that support VRE generation could be unaffordable (Shi et al., forthcoming). Furthermore, the implementation of VRE policy could be hindered by domestic politics.

The innovation of VRE policy in Sri Lanka is a good example for understanding VRE policy development in developing countries, where power systems are less developed, demand response is limited and RE policy is either not in place or not well designed. Sri Lanka is an island country that has isolated power system. Although this country has promulgated one of the highest FITs in the developing world, the development of RE has not been smooth. Wind energy development experienced a stimulated booming by the FITs in 2010 but stopped in 2011. One reason is that the FITs were so high that too many project proposals were submitted and the government could not decide how to select the proposals.

Studies of VRE policy making in Sri Lanka are rare and to the best of our knowledge, no existing study addresses the implications of Sri Lanka's current FIT policy. Although there are some studies examining energy access issues in Sri Lanka, such as Palit (2013), Wijayatunga and Attalage (2002, 2005) and Palit and Chaurey (2011), dedicated studies on Sri Lanka's RE policy are very limited. Findings of early studies of the RE policy, such as (Wijayatunga et al., 2006), are largely outdated due to significant policy and technology changes. Laufer and Schäfer (2011) studied the dissemination process and the use of solar home systems (SHS) in Sri Lanka, and found improved quality of life but not better productivity in agriculture or other productive sectors. Wijayatunga and Prasad (2009) examined the impact of the $10 \%$ non-conventional renewable energy (NCRE) penetration, a mandatory renewable energy portfolio standards (RPS), on system costs of electricity generation and greenhouse gas (GHG) emissions. The study found that the $10 \%$ NCRE target could be achieved with a modest increased cost of only $1.3 \%$ of the total generation cost and that small hydropower is the top priority as the least cost NCRE technology in achieving the target. But wind and hydropower were not in the priority list due to their high costs at that time. The only paper that addresses similar issues to this paper is Wijayatunga (2014), which concluded that the RE policy, regulatory frameworks and related instruments for them have been successful in Sri Lanka. This conclusion, 
however, is not consistent with the experience on VRE policy that was developed after 2010. A few reasons could contribute to the divergence: first, Wijayatunga (2014) paper only observed the RE policy until mid-2011, while the VRE policy was developed after that. Secondly, the cost avoidance principle that has been successful in promoting small hydropower is not effective to VRE development, which is the reason that a technical specific, cost-based, FIT scheme was adopted.

This paper analyses the process of formulating VRE policies in Sri Lanka and examines the lessons and experiences through impact analysis on stakeholders. The information presented in this paper is gathered from a wide range of existing sources, including data from official statistics of the government, an extensive literature review, as well as interviews with key stakeholders in Sri Lanka conducted in September 2014. The experts interviewed are from various energy agencies and independent consultants in Sri Lanka. The major contribution of this paper is to provide an in-depth analysis of recent policy on VRE in Sri Lanka that has not been addressed in the existing literature. The results of the stakeholder analysis are also not available in existing literature and can provide references for future policy making. The lessons and experience in Sri Lanka could be relevant to other developing countries.

The paper is structured as follows. After the introduction, Section 2 reviews the holistic development of the power sector, including VRE development in Sri Lanka. Section 3 critically assesses the development of the RE policy in Sri Lanka. Section 4 conducts a stakeholder impact assessment. Policy implications are summarised in Section 5. The last section concludes the paper.

\section{Development of VRE in Sri Lanka}

\subsection{Overview of Sri Lanka's power sector}

A few characteristics in the Sri Lankan power system are crucial for understanding how the VRE policy has, or should be, developed. Firstly, Sri Lanka is an electricity energy island with no interconnection or electricity trade with any neighbouring countries, although the Asian Development Bank (ADB) has shown interests in financing a submarine cable connection with India. Therefore, all domestic electricity consumption has to be produced within the country. Secondly, electricity in Sri Lanka was mainly generated from hydropower plants until early 2000s, when oil-fired power plants started to play a leading role to meet the quick growth of demand. From 2012, coal-fired power generation has been rapidly growing. Coal-fired power plants have taken the lead role, generating more than $40 \%$ of the national electricity consumption in 2014. Savings due to displacement of expensive oil-fired generation by hydropower are the key incentives for developing RE. Thirdly, there is a huge gap between the evening peak, where the highest daily demand occurs, and the off-peak and thus limit the interconnection of VRE. Lastly, Sir Lanka is a low middle income country where customers are sensitive to electricity prices.

As stated before, hydropower played a dominant role historically although its generation is not stable (Figures 1 and 2). Hydropower plants generated almost all the electricity before 1995 . With the increase of thermal generation capacity, the share of hydropower was reduced to $35 \%$ in 2004 and then remained stable around $40 \%$ until $2010 .{ }^{1}$ Despite having an almost fixed capacity, generation from major hydropower 
plants was fluctuant due to rain fall patterns. Such a significant fluctuation creates risks in the power system and therefore oil-fired power plants were used to balance the demand when hydropower was insufficient.

Figure 1 Total grid connected generation capacity in Sri Lanka (MW) (see online version for colours)

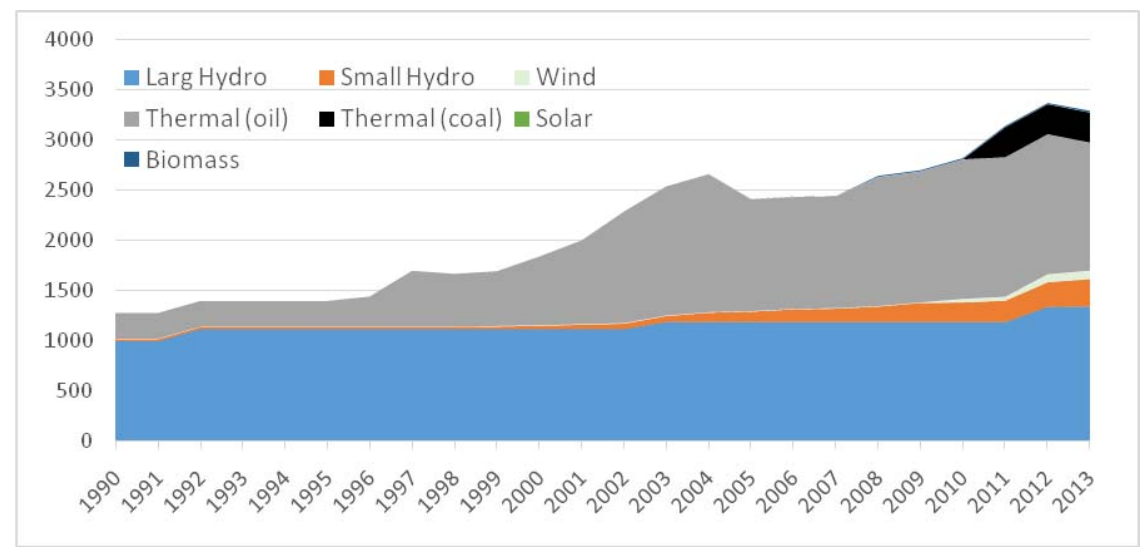

Source: Electricity data (SLSEA, 2014).

Figure 2 Total electricity generation in Sri Lanka by fuel type (see online version for colours)

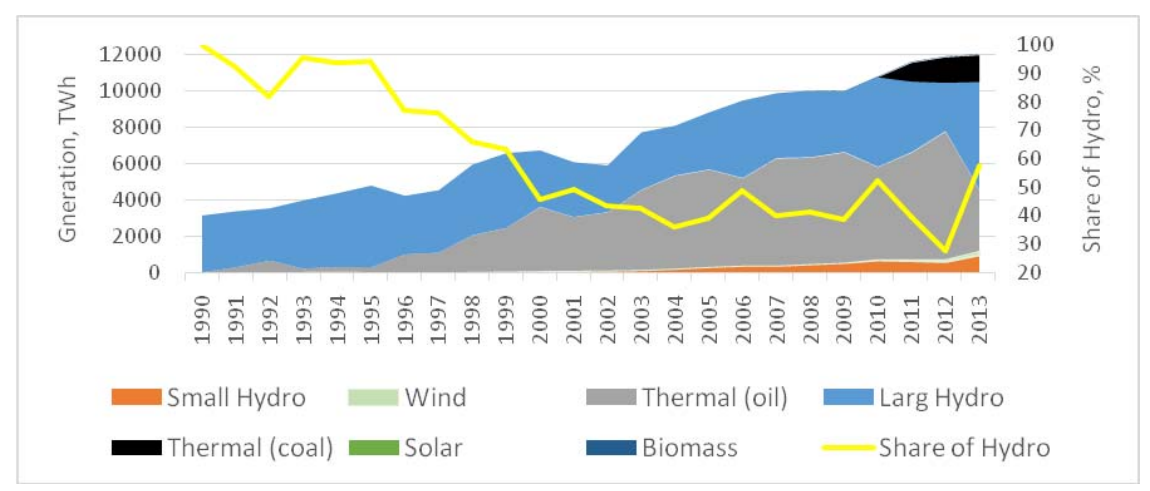

Source: Electricity data (SLSEA, 2014)

The dominant conventional power plants were oil-fired, before coal-fired power generation started to develop in 2011. The first independent power producer (IPP) oil-fired power plant was commissioned in 1997 and the share of oil-fired generation increased since then. By the end of 1999, there were two thermal IPPs in operation with a total of $75 \mathrm{MW}$ capacity. Thermal generation capacity increased dramatically in the 2000 s because of the exponential demand growth, ${ }^{2}$ while the installed capacity of hydropower grew modestly in the past decade due to limited resource available for exploration. In 2000s and until 2012, oil-fired power was almost half of the total electricity generation. Thermal generation was fully oil-fired until 2011 and thus the cost 
of electricity was higher (Figure 1). The high costs of oil-fired power plants motivated the government to build coal-fired power plants, which were first put into operation in 2011.

In terms of grid-connected NCRE generation capacity, small hydropower projects are the major components. Small hydropower capacity has been developed dramatically from 1996 after the introduction of FITs for hydropower. $225 \mathrm{MW}$ of grid connected small hydropower capacity was added between 1998 and 2012 (Figure 1). According to Ceylon Electricity Board (CEB), the grid operator, by 30 June 2014, 282 MW of small hydropower generation capacity was in use and Standardized Purchase Agreements (SPPAs) were signed for another 142.6 MW (CEB, 2014b). Although small hydropower experienced a fast development, its potential has been largely exhausted.

Wind power has been increasing since 2009 and shares the second largest power capacity among the NCRE generation capacities, but significantly less than that of small hydropower. Biomass generation started in 2007 and takes the third place but its share is negligible. On-grid solar PV generation is negligible but is picking up with net metered rooftop solar PV installations (Figure 2).

In addition to supply-side characteristics, Sri Lanka's demand side also has some significant characteristics. There is a huge gap between Sri Lanka's peak and off-peak demands. For example, in 2013, the off-peak demand was less than $800 \mathrm{MW}$ while the peak demand was more than 2,100 MW (Figure 3). Over time, the gap has widened as peak demand increased while off-peak demand remains unchanged.

Figure 3 Typical daily load curve of Sri Lanka in 1997, 2005 and 2013 (see online version for colours)

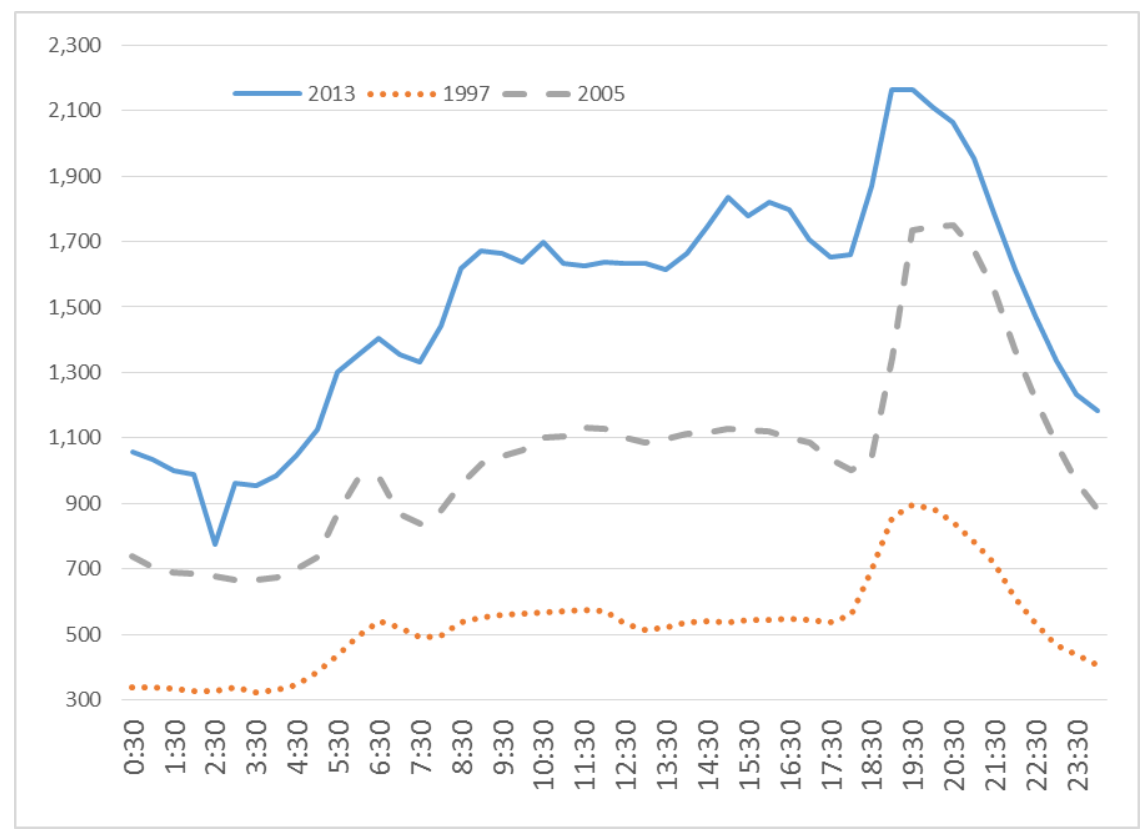

Source: SLSEA (2014) 
Table 1 The current domestic electricity tariffs in Sri Lanka

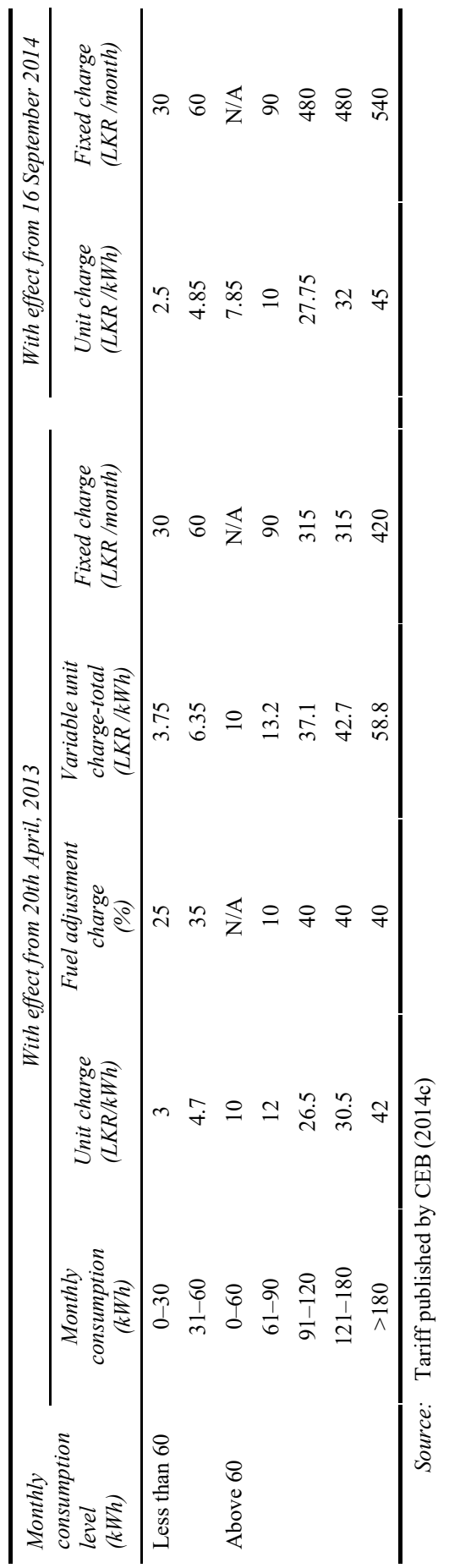


Before September 2014, when the president announced a $25 \%$ price cut of the electricity tariff (Aneez and Sirilal, 2014), Sri Lanka had maintained high electricity prices. The residential sector tariff is also progressive: it adopts an increasing tariff by block and the highest tariff is ten times more than the lowest (Table 1). Commercial tariff is flat and industrial tariff is regressive, but these also vary according to the time of the day (time-of-use tariff).

The CEB and the Lanka Electricity Company Ltd. (LECO) are the only two utilities operating in Sri Lanka. CEB is the major utility in Sri Lanka. It has a large share of power generation, fully owns the coal power plants and the entire transmission network (Wijayatunga and Prasad, 2009). CEB accounted for about $86 \%$ of electricity sales in Sri Lanka and serves $89 \%$ of customers. In contrast, LECO is a distribution company, and only feeds the remaining in urban areas in the western costal belt (Reegle, 2014b). The generation sector has been open to the private sector since the introduction of the first IPP in 1997/1998 (Wijayatunga and Prasad, 2009). However, the state is expected to maintain its dominance in power generation over the long term because the Sri Lanka Electricity Act of 2009 requires the state control of any plant with more than 25 MW capacity.

\subsection{Development of solar $P V$}

Sri Lanka has significant potential of solar power which is costly for the time being. The annual solar irradiation is about 1,642 to $2,190 \mathrm{kWh}$ per square meter $\left(\mathrm{kWh} / \mathrm{m}^{2}\right)$ across the country (Reegle, 2014b), about two times of Germany's average solar irradiation of 975 to $1,200 \mathrm{kWh} / \mathrm{m}^{2}$ (Reegle, 2014a). The spatial variability is relatively small across most of the country, varying at most $20 \%$ to $30 \%$ in any given season (Reegle, 2014b).

Although there is abundant solar energy available for PV applications, the total installed capacity of solar PV is still negligible. However, with the introduction of the net metering and 'electricity banking' 3 mechanism in 2010, distributed rooftop solar PV systems have been becoming popular among households. By the end of June 2014 the total installed capacity of net-metered grid connected solar PV system was approximately $7 \mathrm{MW}$, and has been growing rapidly. Grid-connected centralised solar PV capacity is limited, which was only $0.02 \mathrm{MW}$ in 2010 and only $1.38 \mathrm{MW}$ by the end of 2014. As of 30 June 2014, another 40 MW of solar power projects have signed SPPAs. Despite the country being considered not suitable for the development of concentrated solar power plants, due to low direct normal irradiance (DNI), developers have come forward. This is a clear indication of the knowledge gap on solar resource development that exists in the country. The capacity connected to the national grid, under both the net metering and FIT scheme, is about 8.5 MW (up to November 2014).

Even without FITs, rooftop solar PV in the residential sector will also be developed due to the level of the high residential tariff and the net metering system initiated by the government. For consumers that use more than $180 \mathrm{kWh}$ per month, rooftop solar PV is profitable since their tariff would be around LKR 59 (about 45 US cent) per kWh before the tariff revision in September 2014 and is around LKR 42 per kWh currently (Table 1). Due to limited financial capacity of households, most of those rooftop PV projects are owned and operated by commercial investors and thus the households with PV installations can hardly benefit. Such net metering rooftop solar PV projects, however, are vulnerable to electricity tariff restructuring that reduces the tariff. 
Given the development of coal-fired power plants, retailing electricity prices will drop and thus put residential solar PV projects at risk since their benefits rely on cost saving from avoided purchase of electricity. The first price cut was announced in September 2014 - 25\% average cut of residential tariffs (Aneez and Sirilal, 2014). The price cuts are likely to undermine the development of residential solar PV projects. Other kinds of solar PV projects have been suspended due to concerns about their high costs.

Solar PV, however, are competitive in contrast with oil-fired power and attractive for the households that fall under the highest tariff category (due to high consumption). Solar power has the potential to replace mid-merit power plants running on liquid fuels that come into operation to serve the daytime peak. Solar PV can be considered more feasible for development than wind power because its generation is during the peak demand time while wind power generate more during off-peak hours.

There are arguments for the development of less cost-effective utility scale solar PV projects. Supporters for the development of solar PV with FIT argue for two reasons. First, solar PV will not add pressure to the off-peak excessive supply that usually occurs in the mid-night. Therefore, replacing wind power with solar power will not require curtailment. Another argument is the area with the highest solar potential, Hambantota, is developing fast and solar PV can offer decentralised supply.

\subsection{Development of wind energy in Sri Lanka}

Sri Lanka has abundant potential of cost-competitive wind resources. ADB TA 8167: Capacity Development for Clean Power Development assessed that Sri Lanka has a wind power potential of 5,653 MW, which is about two times of current installed capacity. 375 MW of wind potential has been identified in Mannar Island and is ready to be developed at competitive cost compared to electricity generated from coal. Given the expectation that the wind energy from this island is competitive to coal-fired power, Sri Lanka can produce a significant amount of NCRE technically and economically. A World Bank funded study concluded that $620 \mathrm{MW}$ of wind power could be absorbed by 2020 , which will generate more than $10 \%$ of the total production. But the recommendation was rejected by CEB after considering the system limitations ${ }^{4}$ (Meier, 2012).

So far, however, the on-grid installed capacity of wind power is limited due to a lack of incentives in the old FIT period and limited approval of projects due to system stability constraints and other issues when FIT becomes attractive. The FITs determined under the avoided cost principle, prior to 2010, were not conducive for wind power projects (Abeygunawardana, 2012). Total wind capacity additions between 2000 and 2009 were approximately $3 \mathrm{MW}$ (a demonstration project funded by the World Bank).

Even after the announcement of the 2010 FIT, which is among the highest in the world, the development of wind power has not been smooth. By the end of 2013, the total installed capacity of wind power was more than $81.5 \mathrm{MW}$ (Figures 1 and 2). By 30 June 2014, 98.5 MW of wind power capacity had been commissioned and SPPAs had been signed for another $31 \mathrm{MW}$ (CEB, 2014b). The development of wind power has been suspended twice and is currently waiting for a new policy. The suspension was partly because the applications for wind projects were too many (because the FIT was too attractive) to be accepted. At the time of writing this paper, it was proposed to replace FIT with reverse bidding and development of wind park. 


\subsection{Implications for VRE development}

Even with a large share of hydropower, the Sri Lankan power system has limited flexibility to accommodate future variability of VRE. While hydropower generally is dispatchable, its actual dispatchable capability in Sri Lanka may be low due to cascaded and non-power generation usage of reservoirs. Among the 1,600 MW hydropower capacity, only $250 \mathrm{MW}$ can be used as dispatchable resource during daily power system operation. There are at least three reasons why the share of dispatchable hydropower is small: the reservoirs are cascaded, and thus the operation of individual reservoirs are constrained and the total dispatchable power capacity of the system is limited; large hydropower reservoirs may be used for irrigation purposes and cannot be fully used as dispatchable capacity; and grid-connected small hydropower is not dispatchable. Hydropower generation also suffers from a change of weather patterns. For example, in 2012, there was a significant drop in hydropower generation while in 2013 the output was extremely high (Figure 2). Such an unpredictable (yearly) characteristic demands the presence of expensive, oil-fired power plants to offset the shock and deters development of large scale wind power.

The increasing level of RE penetration will also be limited by the load curve. In terms of RE integration, this load curve means: a large flexible generation capacity is needed because the low electricity consumption level limits the effectiveness of demand side response; solar generation is not helpful in meeting peak demand that occurs in the evening; wind energy will likely not be in demand in the mid-night when off-peak demand is low and minimal loading of coal-fired power plants, or other flexible generation that has obtained long term PPAs will cover the off-peak demand. The isolation of the power system, the huge gap between peak and off-peak demand ( $800 \mathrm{MW}$ vs. peak demand at 2,100 MW) means that during the off-peak period, wind power, once developed, has to be curtailed since minimum capacity from coal-fired power plants and non-dispatchable small hydropower capacities are sufficient for the off-peak demand.

The development of coal-fired power plants that are guaranteed power purchase worsens system flexibility. To reduce generation costs, a key target of energy policy, a $300 \mathrm{MW}$ coal-fired power plant was put into auction in 2011. The capacity of coal power plants reached $900 \mathrm{MW}$ by September 2014, and will be further increased to 1,400 MW in 2017 and 2,000 MW in 2021. Even at the current level (900 MW), assuming a minimum of $70 \%$ utilisation of the generation capacity, the minimum generation capacity from coal would be $630 \mathrm{MW}$, which, together with other non-dispatchable small hydropower projects that have obtained PPAs, would leave no room for NCRE during the off-peak period.

\section{RE policy making in Sri Lanka}

\subsection{Sri Lanka's energy policy making framework}

The Sri Lankan Government is governed by a presidential system: the executive power of the state is vested with the president while the legislative power is exercised by the parliament. Within the government, general energy policies are decided by the Ministry 
of Power and Energy. Regulatory roles are carried out by the Public Utility Commission of Sri Lanka (PUCSL).

RE policy was determined by the Ministry of Power and Energy until 2012, when the Ministry of Environment and Renewable Energy was created and took over the policy making on RE. The Sustainable Energy Authority (SEA) ${ }^{5}$, which became operational at 1 October 2007, is mandated to develop and implement the country's RE policy, demand-side energy-efficiency improvement, and energy conservation (Reegle, 2014b).

PUCSL plays a key role in RE policy by setting FIT rates. PUCSL was established as the regulator for the energy and water sectors, under the PUCSL Act 2002. Its roles were further enhanced by the Electricity Reform Act 2002 to issue licenses and determine electricity tariffs. Initially, the roles of PUCSL were only limited to advising the government on policy decisions, including tariff settings. The lack of full execution of its roles was due to failure of the previous sector reform program. The roles of PUCSL have been full after the implementation of the Sri Lanka Electricity Act 2009, which replaces the Electricity Reform Act 2002 (Reegle, 2014b). The Sri Lanka Electricity Act 2009 separates functions - operation, regulation and policy making - in the electricity industry. It also tasks the PUCSL to undertake technical, safety and regulation of the electricity industry as well as protection of consumer interests. Since 2010, PUCSL was tasked to approve/disapprove proposal of tariff that is made by CEB.

\subsection{Evolvement of FIT policy in Sri Lanka}

Although Sri Lanka shows a very promising potential for RE development, it is still a challenge to create a framework for its promotion to ensure the sustainability of the RE industry without external financing, while maintaining the current momentum of RE development (Reegle, 2014b).

Sri Lanka has identified the development of RE supply for electricity (RES-E) as a policy to diversify the power sector from high cost thermal power generation. The National Energy Policy 2006 has identified fuel diversity and energy security in electricity generation as strategic objectives and the development of RE projects was identified as a part of this strategy.

The National Energy Policy and Strategies updated in 2010 set share of NCRE targets in on-grid power supply as $10 \%$ by 2016 , and $20 \%$ by 2020 . Ten percent of total electricity generation, however, was already achieved by December 2013 when NCRE generation capacity was $375 \mathrm{MW}$.

From 1996 to 2007, Sri Lanka adopted the cost-avoided principle to determine the FIT (with SPPA for 15 years) to encourage the private sector establishment of RE power plants with a capacity below $10 \mathrm{MW}$. However, other than for small hydropower, the avoided cost tariff was not adequate to balance out the costs of RE technologies (Abeygunawardana, 2012). Therefore, after the introduction of the initial FIT, only small hydropower plants were notably developed (Figure 1).

In 2010, Sri Lanka launched a program of FITs and has now one of the highest tariffs in the developing world. Recognising the limitations of the initial FIT, the FIT system was changed from an avoided cost FIT to a technology-specific cost-based FIT from 2007 (but the first new FIT was only announced in 2010) for NCRE with capacity less than $10 \mathrm{MW}$. CEB is obliged to make SPPAs for electricity generated from NCRE sources, signed on or after the 25 November 2010. 
The tariffs are cost-based and technology-specific. Tariffs for eight technologies have been declared, but solar PV has not been included due to its high tariff resulting from high capital costs. The government however, has introduced a tariff cap with a SPPA period of 20 years for any other RE technologies that does not have a declared tariff. SPPAs for Solar PV technology can be signed under this category.

The initial Sri Lanka FIT program has two tracks, a fixed-price (flat tariff) track without inflation protection (identical to the German FIT but without degression rates) and no degression rate, and a three-tier tariff track that varies the tariff according to the price of the base fuel rate, operations and maintenance, and the year of operation (Table 2). The developers have the freedom to choose either the three-tier tariff track or the flat tariff track. CEB is obliged to purchase electricity generated from NCRE for a period of 20 years and this period is extendable by mutual consent (Reegle, 2014b).

However, the implementation of the new tariff is not smooth. Between 2010 and 2012, there were no FITs published because CEB challenged the rights of PUCSL in setting tariffs (Jayasinghe, 2014). Even the revised FITs were initially announced in 2012, the implementation of the FIT scheme was suspended before CEB announced the new FIT at the end of 2014. The minister in charge of power and energy ordered a stop to the issuance of new wind project permits in 2011 due to concerns over passing the incremental costs on to consumers after the costs failed to be passed on to Sri Lanka Sustainable Energy Authority (SLSEA) (Meier, 2012).

Table 2 NCRE tariff for 2012-2013 (LKR/kWh)

\begin{tabular}{lccccc}
\hline \multirow{2}{*}{ Technology } & \multicolumn{3}{c}{ Option 1: Three-tier tariff } & & Option 2: Flat tariff \\
\cline { 2 - 4 } & \multicolumn{3}{c}{ Fixed rate } & & All inclusive rate, \\
\cline { 2 - 3 } & $16.81(12.64)$ & $6.38(5.16)$ & $5.8(1.68)$ & & $16.7(13.04)$ \\
\cline { 2 - 3 } Mini-hydropower & $17.27(12.92)$ & $6.55(5.28)$ & $5.95(1.68)$ & & $17.15(13.32)$ \\
Mini-hydropower-local & 15 & & \\
Wind & $22.63(17.78)$ & $8.58(7.26)$ & $7.8(1.68)$ & & $20.62(19.43)$ \\
Wind-local & $23.29(18.28)$ & $8.83(7.47)$ & $8.03(1.68)$ & & $21.22(19.97)$ \\
Biomass (Dendro) & $9.8(9.10)$ & $3.72(3.10)$ & $3.38(1.68)$ & & $25.09(20.70)$ \\
Biomass (Waste) & $9.8(4.55)$ & $3.72(3.10)$ & $3.38(1.68)$ & & $17.71(14.53)$ \\
MSW & $19.8(15.16)$ & $7.51(6.19)$ & $6.83(1.68)$ & & $26.1(22.02)$ \\
Waste Heat & $10.19(7.13)$ & $3.86(2.65)$ & $3.51(1.68)$ & & $9.19(6.64)$ \\
\hline
\end{tabular}

Notes: Numbers in () are FITs for 2010.

MSW: municipal solid waste.

*Escalation rate for 2012 was specified at $5.09 \%$.

Scalable rate was not reported to save space.

Source: PUCSL (2012)

CEB implemented a revised FIT in later 2014 according to the cabinet approval dated on 7 March 2014 (Table 3). The FITs are applicable to projects starting from 1 January 2012. The same starting date as the previous FIT scheme (2012-2013) (Table 2) indicates that the 2014 FIT plan is a correction to the previous one. In the revised FIT plan, the fixed rate option is no longer available. Both the fixed rate and scalable rates are reduced. 
Table 3 NCRE tariff from 2012 (revised in 2014) (LKR/kWh)

\begin{tabular}{lccccc}
\hline \multirow{2}{*}{ Technology/source } & \multicolumn{2}{c}{ Non-scalable (fixed rate) } & \multicolumn{2}{c}{$\begin{array}{c}\text { Scalable base } \\
\text { O\&M rate } \\
\text { (year 1-20) }\end{array}$} & $\begin{array}{c}\text { Scalable base } \\
\text { fuel rate } \\
\text { (year 1-20) }\end{array}$ \\
\cline { 2 - 5 } Mini-hydropower & 15.56 & 5.98 & 3.40 & 1.83 & None \\
Mini-hydropower-local & 15.97 & 6.14 & 3.49 & 1.88 & None \\
Wind & 22.05 & 8.48 & 4.82 & 1.30 & None \\
Wind-local & 22.60 & 8.69 & 4.94 & 1.33 & None \\
Biomass & 9.67 & 3.72 & 2.11 & $1.52\left(1.90^{*}\right)$ & 12.25 \\
Agro and industrial waste & 9.65 & 3.71 & 2.11 & $1.52\left(1.90^{*}\right)$ & 6.13 \\
Waste heat & 9.14 & 3.52 & 2.00 & 0.48 & None \\
Escalation rate for year 2013 & & & & $5.16 \%$ & $3.44 \%$ \\
\hline
\end{tabular}

Notes: Any other RE technology would be offered a flat tariff of LKR 23.10/kWh

(non-scalable for 20 years).

*For 16 years onwards.

Source: CEB (2014a)

\subsection{Controversies of the FIT policy}

The current FIT scheme has a few problems. Firstly, it is so attractive that too many investors apply for solar and wind projects to be accepted. Secondly, probably due to currency depreciation, the basic FIT rates actually increased (to match with costs of imports), which could not respond to frequent cost changes due to technology development. Thirdly, FITs cannot be adjusted to the demand for capacity. Because of these, current targeted capacity is easily exceeded, due primarily to profitable FIT. Meanwhile, a lack of competitive mechanisms to allocate and limit quota causes RE development to go into deadlock and is subsequently suspended. This is a live example that excessive FIT could actually deter the development of RE.

It is still debated as to whether FITs should be kept. Attorney-General's Chambers (AGC) has ruled that investors for new energy projects must be determined by tenders and FIT is against the law and should not be continued (Wijedasa, 2014). Given the good wind resources in Mannar Island and other places, during the authors' interviews and the workshop in September 2014, many people expressed that they are in favour of using competitive bidding to decide wind power prices. By doing this, there will not be the need for unnecessarily high FIT payments. It will also help the government to control the total capacity of VRE and adjust it to the appropriate level. The RE master plan has revealed whether, and how much VRE can be integrated into the grid system. Given the premier resource endowment, it would be more appropriate to develop large resources with competitive bidding and thus FIT is not necessary.

However, a few people still argued that the FIT tariff system is appropriate for small wind and solar PV projects which are not attractive to investors. The assertion is made based on the creation of opportunities for local private investors who are not competitive with international investors. The local industry prefers FIT to reverse bidding which is under consideration as FIT is limited to $10 \mathrm{MW}$ and thus foreign investors may not be interested in it. In the case of rooftop solar PV, a FIT would also be preferred to the 
current net metering program as FIT makes it possible for underprivileged families to gain access to funding and thus they can benefit from the projects.

\section{Stakeholder impact assessment of Sri Lanka's VRE policy}

\subsection{Costs allocation}

Sri Lanka proposed establishing a sustainable finance source for RE support schemes, that is pass the costs on to petroleum consumers. But later the levy proposal was not implemented amidst concerns that petroleum prices were already high. The low income level in Sri Lanka suggests that there is a low purchasing power. In 2010, about $24 \%$ of the population was still living under the $\$ 2$ a day (PPP) poverty line (World Bank, 2014). A 2011 PUCSL consultation report finds that $42 \%$ of households consume (50\% when un-electrified households are counted) less than the minimum requirement $(12 \mathrm{kWh}$ per person per month) and the poorest face challenges in securing their basic electricity needs (Ranasinghe, 2011). Further increase of electricity tariff leads to more poverty and raises barriers to electricity access. The affordability and poverty concerns could be one of the reasons that lead to the suspension of new wind project permits after 2011 (Meier, 2012).

Whether NCRE is more expensive or not is still debatable in Sri Lanka. Although NCRE is still more expensive than coal-fired and hydropower generation (Jayasinghe, 2014), the cost gap could be diminished if inflation of NCRE costs due to private investment, underestimated coal power generation costs under state ownership and cheap financial costs were taken into consideration (Jayasinghe, 2014). Furthermore, NCRE has a much richer remaining potential than hydropower does. Therefore, NCRE will be the cost effective option for future generation-capacity expansion. Others argue that NCRE is cheaper when compared with oil-fired power (PUCSL, 2014).

This state ownership allows all the costs to the grid operator, CEB, to be either born by the budget, or by the consumers. Considering the current high generation costs from oil-fired power plants (average LKR29.29/kWh; PUCSL, 2014; VRE may be developed without additional costs to consumers). Although in comparison with hydropower and coal-fired electricity, electricity from VRE is relatively expensive, it is cheaper than electricity from oil-fired power generation. It has been argued that NCRE will enjoy much higher generation costs-saving at the immediate future when it replaces oil-fired power generation, but the savings will decrease in the long run when it is expected to replace coal-fired power plants ${ }^{6}$ (Nexant, 2014). Furthermore, if the current government subsidies can be redirected from diesel generators to RE power generators, the country may be able to harness more VRE power without incremental subsidies.

\subsection{Household consumers}

In Sri Lanka, the industrial sector that engages in export is not that outstanding and thus the analysis of impact is focusing on households. Currently, consumers benefit from government subsidies from two perspectives. On the one hand, on average, the government subsidises electricity generators through the debt write-off and the moratorium and concessionary pricing of fuel oils. 
According to an early report from PUCSL (2010), in 2011, the actual cost was about LKR 19.14 per $\mathrm{kWh}$, while the electricity tariff was only LKR $14.95 / \mathrm{kWh}$. The electricity tariff was subsidised by $21.9 \%$ (LKR 4.19 per $\mathrm{kWh}$ ) in 2011 . On the other hand, lower consumption consumers pay lower tariffs than the average cost. Currently, the lowest tariff (for households consume less than $30 \mathrm{kWh} /$ month) is LKR $3 / \mathrm{kWh}$ while the national average generation cost is LKR 12.65/kWh (PUCSL, 2014). Given the current low tariff level for low consumption families, the future adjustment of tariffs would be a crucial factor in shaping the impact.

It is possible that the development of net metering solar PV projects may indirectly lead to price hikes for low-level electricity users, who are often poor families and may aggravate social inequality. With the reduced consumption of high tariff users, electricity tariffs will have to be increased for those with low consumption. Sometimes, low income households are charged to compensate the financial loss and thus solar PV projects will make the poor pay even more than before. During the interviews in September 2014, it is revealed that many distributed solar panels may be owned by external private investors instead of the households that installed the panels on their rooftops because many families cannot afford to buy PV panels. If that is the case, the benefits of distributed generated PV would not be channelled to those families with solar PV.

In the case of solar house system, although the introduction of technology in remote rural areas of Sri Lanka is combined with the provision of microloans, it has been found that poor SHS users do not have the financial resources to replace malfunctioning equipment during the period of loan repayment (Laufer and Schäfer, 2011).

If Sri Lanka wants to develop solar PV technologies without regressive impacts on households, the government needs to adopt cost reflective FIT to replace net metering scheme for at least roof-top PV installations. In a net metering scheme, which is assisted by the 'electricity banking' scheme, under-privileged households will benefit from subsidised tiered electricity tariff because their tariff level is low and thus is less likely to install rooftop PV. FIT can provide stable revenues and thus make it possible for households to receive funding from commercial banks. By doing this, the benefits of solar PV can be distributed more evenly than the banking projects because underprivileged families now have the chance to install solar PV.

\subsection{Conventional power generators}

Although the growth of coal-fired power plants started from 2011, the typical conflicts between coal power plants and VRE have already appeared. Currently, CEB tends to prioritise coal-fired power plants in dispatch based on its low operating cost and the argument that coal-fired power plants cannot be ramped down below a technical limits (no more than 30\%) and an economic reasonable baseline. Since the survival of coal power generators are prioritised, the curtailment clause is proposed by CEB for future NCRE projects, in particular, wind projects. Given CEB's role both as owners of those coal power plants and as a transmission operator, coal power plants have chance to get preferential treatment, although there is no such practice at the moment.

However, there are also discussions to convert some oil-fired power plants into gas-fired plants through imported LNG in order to reduce the operating cost of these combined cycle power plants. While gas-fired power plants can be useful for peak demand and load following operation, they are too expensive to be used as base load. 
Those gas-fired power plants may be conducive for RE due to their ability to absorb intermittency of VRE.

Oil-fired and hydro power plants are dispatchable capacities to complement the intermittence of VRE. In the Sri Lankan case, actually, the fluctuation of electricity generation from solar PV is compatible with oil-fired power plants and thus could be developed without additional costs. Since CEB is the owner of these coal-fired power plants and grid operators, and there is a pressure to reduce electricity cost, it would be difficult for CEB to balance between VRE and coal-fired power plants.

\subsection{The grid operator: $C E B$}

The solar rooftop projects create significant challenges for CEB. Although the grid operators (CEB) will not pay for electricity from those rooftop PV, it suffers the loss of premier consumers and thus incurs financial loss from forgone revenue as well as costs to maintain the transmission and distribution system to support import and export of electricity by net metered customers and spare generation capacity to cater to net metered consumers' demand during the peak hours at free of charge. With the current tariff (Table 1) and average generation cost of $12.64 \mathrm{LKR} / \mathrm{kWh}$ (CEB, 2014b), in the residential sector, CEB can only reap profits from those households that consume more than $90 \mathrm{kWh}$ per month while losing money to those households that consume less than $90 \mathrm{kWh}$ per month. Thus the distributed rooftop projects will remove high electricity users and threaten the CEB's financial status.

For the development of wind power, CEB faces the balance between curtailing low marginal cost (i.e., cheap) wind power and reduction of coal-fired power plants. If the curtailment condition is accepted by wind developers, CEB will not face financial losses, although nationally some economic benefits will be forgone.

Since the costs of electricity and subsidies to CEB are closely monitored, CEB has strong interest to reduce purchase and transmission costs. Therefore, there is an argument that NCRE may not be affordable by CEB. Some people argue that CEB can afford renewable power if it can afford oil-fired thermal power since the energy that CEB purchased from RE private power producers are cheaper than any oil-fired power plants. If VRE power is used to substitute the oil-fired power generation system, then an increase of VRE and cost savings may be achieved simultaneously. However, the development of coal dramatically changed people's expectation: cheap coal-fired power replacing oil-fired power becomes the baseline and thus CEB's argument has a point.

\section{Discussion and policy implications}

The experience of developing VRE policy in Sri Lanka's has a few implications for public policy. First of all, a better coordination among governing agencies is necessary for a successful policy innovation. Although the Sri Lankan Government has realised the need to develop cost reflective FITs for VRE, the policy has not been developed in the first few years, largely because of conflicts within government agencies. The power of setting tariff by PUCSL was challenged by CEB and consequently no FITs was published between 2010 and 2012 (Jayasinghe, 2014). This delay could be avoided by better coordination within the government. 
Furthermore, policy instruments need to match the technical characteristics of VRE. In the case of developing VRE, cost reflective FIT policy is needed. Although the cost avoided FITs were effective in developing small hydropower due to the lower cost characteristic of small hydropower, it could not promote the development of VRE because the costs of which are much higher than the avoided costs from fossil fuel generation.

In addition, policy designs must include the potential of rapid decline of VRE costs into the consideration. Unlike other traditional energy sources, VRE source power generation has experienced dramatic cost reduction in the past. For example, in Germany, the world's pioneer in solar PV development, the investment costs for PV installations have fallen by an average of $13 \%$ annually since 2006 . The cost reduction was above $30 \%$ in 2009 (Fraunhofer ISE, 2014). Failure to prepare for such cost reduction caused a bubble and the subsequent bubble burst in Italy and Spain (Río and Mir-Artigues, 2014). Germany, in contrast, induced a breathing cap mechanism to keep the total capacity under control (German Energy Blog, 2014). When Sri Lanka published its FITs for wind power, it fails to keep pace with the costs of wind power and was thus forced the suspension of wind policy. A mechanism that endogenously sets the rate at an efficient level is helpful for improving energy policies. The degression rates should be scalable so that FIT costs do not go out of control and generate windfalls for investors. This could be achieved if FITs for new installations were adjusted regularly and coordinated to respond automatically according to observed target deployment levels. It would be better if Sri Lanka has used other market mechanism, such as biding, for its wind power project given its premier wind resources.

Fourth, subsidy policy should be designed in such ways that the development of VRE can be encouraged without significantly distorting the electricity market. Although for sustainable funding of RE, costs have to be passed on to consumers directly or indirectly, to whom the costs will be passed have different implications. Costs may be added to consumers' electricity bills directly, or directly included as levies for petroleum product consumers. The direct pass -on could lead to unaffordability which is not the desirable result for public policy. RE generation could also be financed with levies on petroleum products that are used for transportation, which can have double benefits: the discouragement of fossil fuels use and encouragement of RE development. The burden would also likely fall on richer people who own vehicles and thus do less harm to the poor. Unfortunately, Sri Lanka failed to enforce the petroleum levies. On the contrary, it still maintains subsidy to fuels for power generation. An option nowadays for Sri Lanka would be financing the VRE costs indirectly through cost-saving measures or utilising avoided subsidies. Given the significant subsidies to oil-fired power generation through support of fuel oil, the government can divert the avoided subsidies to support RE, or more dramatically, remove all support to generate fuels and use the saved budget to finance RE support policy.

\section{Concluding remarks}

Sir Lanka's case demonstrates that how public policy for VRE could be improved. VRE policy could lead to overheated response from the market, which is unfavourable from public policy's perspective. Cost containment mechanisms are important to make sustainable VRE policy. It also demonstrates that a lack of coordination among different 
government agencies could make VRE policy not workable. It is also shown that a successful VRE policy should address the concerns of each stakeholder for feasibility and social concerns.

Although Sri Lanka has the potential to achieve much more ambitious VRE targets, the potential has not been fully developed due to poorly-structured policy. For the future, this paper proposes some generation policy implications for the promotion of VRE: prepare better coordination among government agencies; set cost reflective and technology specific policy; install capacity and costs containment mechanism; and establish appropriate cost sharing scheme.

There is a need to have policy framework which is backed-up by realistic regulatory and legal instruments to make such policy practical. The costs of RE support mechanisms should be planned, monitored and reviewed to make sure RE remains affordable and sustainable. Counties that are sensitive to cost may introduce cost ceilings, whereby a certain amount of support is available and granted on a first-come, first-served basis, or through auctions. The distribution of costs and benefits among households should be assessed. The impact on low income household should be particular watch out to avoiding energy poverty. Financing RE support with levies on fossil fuels is also suggested.

\section{Acknowledgements}

The authors owe gratitude to Yongping ZHAI from the Asian Development Bank for his guidance and advice on the study and to Ranishka Wimalasena and Hannelli Austria for facilitating the field work. The authors also acknowledge and express their sincere appreciation and gratitude for the insights shared by Priyantha Cabral Wijayatunga, Manjula Perera, M.M.R. Pathmasiri, Upali Daranagama, Sunith Fernando, Swetha Perera, Sujeewa Abeywickrama, and Noel Priyantha during the interviews with them. The constructive comments from Kazuhiro Enomoto, Shannon Cowlin, Swetha Perara, Paul Hattle, and Ranishka Wimalasena are also highly appreciated.

\section{References}

Abeygunawardana, A. (2012) Feed-in-tariff in Sri Lanka, Energy Forum [online] http://www.efsl.lk/reports/Feed\%20In\%20Tariff\%20in\%20SL.pdf (accessed 9 October 2014).

Aneez, S. and Sirilal, R. (2014) 'Sri Lanka cuts energy price after start of Chinese-funded coal power plant', Reuters, 16 September.

CEB (2014a) Non Conventional Renewable Energy Tariff Announcement, Ceyron Electricity Board, Colombo [online] http://www.ceb.lk/download/db/ncre tariff.pdf (accessed 28 December 2014).

CEB (2014b) Present Status of Non-Conventional Renewable Energy Sector (as at 30/06/2014), Ceylon Electricity Board [online] http://www.ceb.lk/sub/db/op_presentstatus.html (accessed 30 September 2014).

CEB (2014c) Tariff Plan, Ceylon Electricity Board [online] http://www.ceb.lk/sub/residence/ tariffplan.html (accessed 30 September 2014).

Fraunhofer ISE (2014) Recent Facts about Photovoltaics in Germany, July, Fraunhofer-Institut für Solare Energiesysteme ISE, Freiburg. 
German Energy Blog (2014) Overview Renewable Energy Sources Act [online] http://www.germanenergyblog.de/?page_id=283 (accessed 23 September 2014).

IEA and IRENA (2016) IEA/IRENA Joint Policies and Measures Database [online] http://www.iea.org/policiesandmeasures/renewableenergy/ (accessed 28 March 2015).

Jayasinghe, P. (2014) No Shortage of Indigenous Renewable Resources [online] http://www.ft.lk/ 2014/05/02/no-shortage-of-indigenous-renewable-resources/ (accessed 30 September 2014).

Laufer, D. and Schäfer, M. (2011) 'The implementation of solar home systems as a poverty reduction strategy - a case study in Sri Lanka', Energy for Sustainable Development, Vol. 15, No. 3, pp.330-336.

Meier, P. (2012) Sri Lanka and Vietnam: Lessons of the Renewable Energy Tariff Experience [online] http://siteresources.worldbank.org/INTENERGY2/Resources/41141911328286035673/D1_Peter_Meier.pdf (Accessed 30 July 2014).

Nexant (2014) Capacity Building for Clearn Power Development Part A: Sytem Stablity and Network Planning Studies - Final Report, Unpublished.

Palit, D. (2013) 'Solar energy programs for rural electrification: experiences and lessons from South Asia', Energy for Sustainable Development, Vol. 17, No. 3, pp.270-279.

Palit, D. and Chaurey, A. (2011) 'Off-grid rural electrification experiences from South Asia: status and best practices', Energy for Sustainable Development, Vol. 15, No. 3, pp.266-276.

PUCSL (2010) Consultation Paper on Setting Tariffs for the Period 2011-2015, Public Utilities Commission of Sri Lanka, Colombo.

PUCSL (2012) Decision on Non-Conventional Renewable Energy Purchase Tariffs 2012-2013, Public Utilities Commission of Sri Lanka, Colombo.

PUCSL (2014) Generation Performance in Sri Lanka 2013 (First Half) Public Utilities Commission of Sri Lanka [online] http://www.pucsl.gov.lk/english/wp-content/uploads/ 2014/03/Gen-Performance_2013-First-Half.pdf (accessed 30 September 2014).

Ranasinghe, A. (2011) Study on Requirements of Prospective Electricity Consumers and Fuel (Electricity) Poverty \& Affordability, Public Utilities Commission of Sri Lanka, Colombo.

Reegle (2014a) Energy Profile Germany, Renewable Energy \& Energy Efficiency Partnership (REEEP) Policy Database [online] http://www.reegle.info/countries/germany-energyprofile/DE (accessed 19 August 2014).

Reegle (2014b) Energy Profile Sri Lanka, Renewable Energy \& Energy Efficiency Partnership (REEEP) Policy Database [online] http://www.reegle.info/countries/sri-lanka-energyprofile/LK (accessed 14 May 2014).

Río, P.D. and Mir-Artigues, P. (2014) A Cautionary Tale: Spain's Solar PV Investment Bubble, International Institute for Sustainable Development Global Subsidies Initiative, Geneva.

Shi, X. (2016) 'The future of ASEAN energy mix: a SWOT analysis', Renewable and Sustainable Energy Reviews, Vol. 53, pp.672-680.

Shi, X., Liu, X. and Yao, L. (forthcoming) 'Assessment of instruments in facilitating investment in off-grid renewable energy projects', Energy Policy.

SLSEA (2014) Electricity Data, Sri Lanka Sustainable Energy Authority [Online] http://www.info.energy.gov.lk/ (accessed 28 July 2014).

Wijayatunga, P.D.C. (2014) 'Regulation for renewable energy development: lessons from Sri Lanka experience', Renewable Energy, Vol. 61, pp.29-32.

Wijayatunga, P.D.C. and Attalage, R.A. (2002) 'Analysis of household cooking energy demand and its environmental impact in Sri Lanka', Energy Conversion and Management, Vol. 43, No. 16, pp.2213-2223.

Wijayatunga, P.D.C. and Attalage, R.A. (2005) 'Socio-economic impact of solar home systems in rural Sri Lanka: a case-study', Energy for Sustainable Development, Vol. 9, No. 2, pp.5-9.

Wijayatunga, P.D.C. and Prasad, D. (2009) 'Clean energy technology and regulatory interventions for greenhouse gas emission mitigation: Sri Lankan power sector', Energy Conversion and Management, Vol. 50, No. 6, pp.1595-1603. 
Wijayatunga, P.D.C., Siriwardena, K., Fernando, W.J.L.S., Shrestha, R.M. and Attalage, R.A. (2006) 'Strategies to overcome barriers for cleaner generation technologies in small developing power systems: Sri Lanka case study', Energy Conversion and Management, Vol. 47, pp.1179-1191.

Wijedasa, N. (2014) 'SEA, CEB in heated exchange over wind park project', The Sunday Times.

World Bank (2014) World Development Indicators 2014, The World Bank, Washingtong, DC.

\section{Notes}

1 Prior to 2010 during dry years (low rainfall), Sri Lanka experienced load shedding due to shortage of hydropower generation. Therefore, along with reduction in generation at hydropower plants, national total generation also reduced. This caused fluctuations in percentage of hydropower generation to be minimum. Commissioning of the Kerawalapitiya power plant (300 MW) in 2010 and phase 1 of Norochcholai Power Plant (300 MW) in 2011 have minimised the requirement of load shedding during dry years. Therefore, the reduction in national total generation was very much lower compared to reduction in generation at hydropower stations

2 The growth was driven by the extensive expansion of the national grid to electrify households. The growth rate will fall since electrification rate has approached $100 \%$.

3 Under the 'net metering' scheme, the benefit to investors is the avoided purchase from the grid. Once the retailing tariff is reduced, the benefit will be reduced and thus the project could be no longer financially viable. In contrast, a FIT scheme will fix the benefit and thus provide certainty for investors. The rooftop projects will face reduced return. Under the 'electricity banking' scheme, electricity that is exported to the grid will not be purchased by CEB. It is saved and can be used later on (such as in the night).

4 Other independent experts think at most $100 \mathrm{MW}$ can be absorbed due to uncompetitive costs of other hydropower additions which have zero variable fuel cost.

5 SEA was converted from Energy Conservation Fund, a unit under the Ministry of Power and Energy, through legislation.

6 According to this Nexant study the avoided cost of RE is expected to reduce as time progresses, beyond year 2021, the avoided cost of RE would be 5-6 US cents. 